LA W RENCE LIVERM ORE N A TIO NAL LABORATORY

\title{
Ag BL Description for General Atomics
}

C. Huntington

December 12, 2013 
This document was prepared as an account of work sponsored by an agency of the United States government. Neither the United States government nor Lawrence Livermore National Security, LLC, nor any of their employees makes any warranty, expressed or implied, or assumes any legal liability or responsibility for the accuracy, completeness, or usefulness of any information, apparatus, product, or process disclosed, or represents that its use would not infringe privately owned rights. Reference herein to any specific commercial product, process, or service by trade name, trademark, manufacturer, or otherwise does not necessarily constitute or imply its endorsement, recommendation, or favoring by the United States government or Lawrence Livermore National Security, LLC. The views and opinions of authors expressed herein do not necessarily state or reflect those of the United States government or Lawrence Livermore National Security, LLC, and shall not be used for advertising or product endorsement purposes.

This work performed under the auspices of the U.S. Department of Energy by Lawrence Livermore National Laboratory under Contract DE-AC52-07NA27344. 
The Material Strength campaign at LLNL is an effort to measure the resistance of materials to deformation when placed under large stresses. These experiments are carried out at large laser facilities, where a laser-driven plasma pusher creates a pressure in excess of 5 Mbar (on the NIF) or 1 Mbar (at OMEGA) in the sample of interest. Strong materials resist deforming in response to these high pressures, and the magnitude of the strength can be inferred using an $\mathrm{x}$-ray probe traversing the sample. The x-ray source used for this probe must be bright, high-energy, and spatially coherent. To achieve all of these things, silver micro-wires and micro-flags are an essential diagnostic tool.

Silver is an ideal material for this work because the characteristic x-ray emission energy from silver $(\sim 22 \mathrm{keV})$ is high enough to penetrate $\mathrm{x}$-ray opaque materials of interest, including tantalum. This is in contrast to lower atomic number elements that are commonly used as $\mathrm{x}$-ray sources, for example titanium or copper, which do not produce x-rays of sufficiently high-energy. Conversely, higher atomic number materials like tungsten and gold do not produce line-emission $\mathrm{x}$-rays as efficiently as silver, and thus produce $\mathrm{x}$-ray sources which are not bright enough for the material strength experiments. Finally, silver x-ray sources can be fabricated accurately in a range of geometries, from tiny wires to thin foils, each of which has been used for measurements of material strength in laser experiments.

This work was performed under the auspices of the U.S. Department of Energy by Lawrence Livermore National Laboratory under Contract DE-AC52-07NA27344.

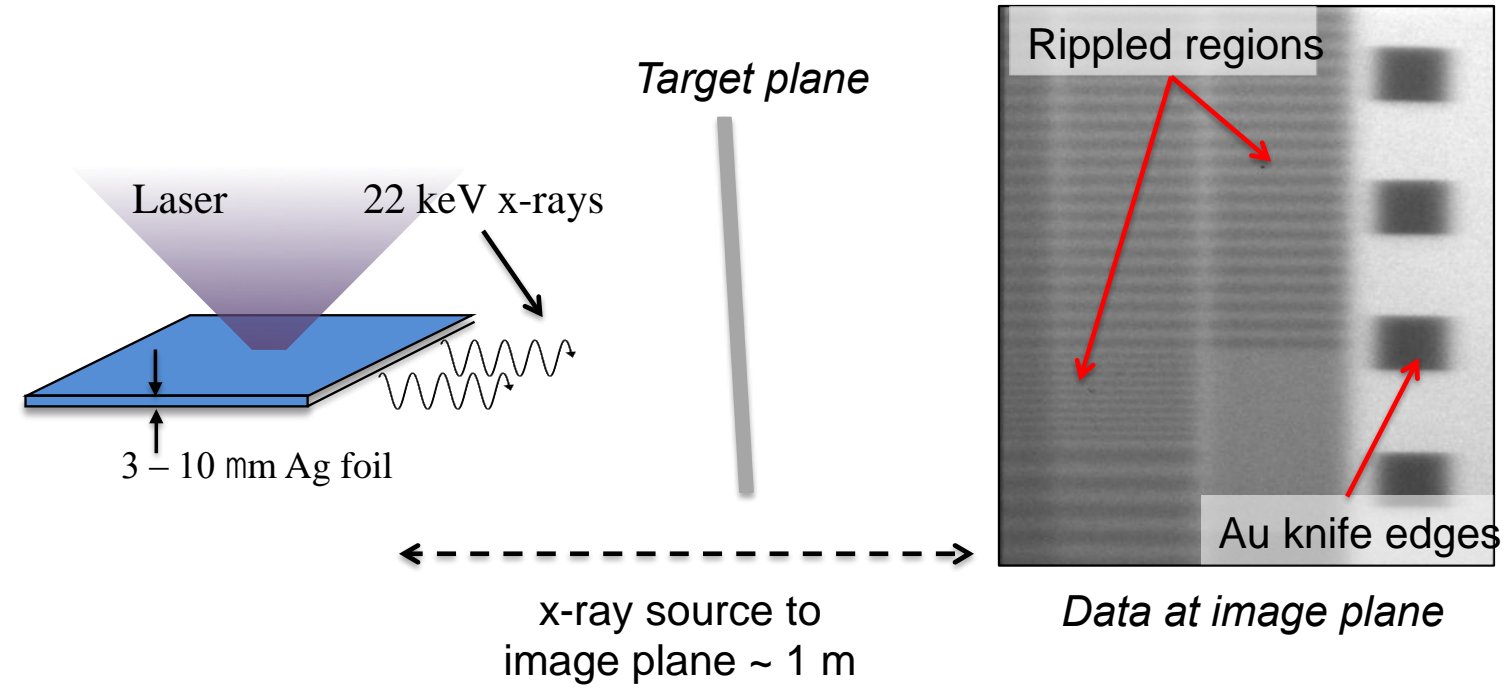

Figure: Geometry for Ag NIF experiments. A 3 or 10 micron-thick Ag foil is laserirradiated to produce $22 \mathrm{keV} x$-rays. The $\mathrm{x}$-rays pass though the sample of interest and are recorded on an image plate detector. 